\title{
Progress in Gas/Solid Interface Charging Phenomena
}

\author{
Shakeel Akram $₫$, Jérôme Castellon *®i] and Serge Agnel 1 \\ Institut d'Electronique et des Systèmes, University of Montpellier, 34095 Montpellier, France; \\ akram@ies.univ-montp2.fr (S.A.); serge.agnel@umontpellier.fr (S.A.) \\ * Correspondence: jerome.castellon@umontpellier.fr
}

Received: 13 October 2020; Accepted: 1 December 2020; Published: 3 December 2020

check for updates

\begin{abstract}
Surface charge accumulation in the spacer modifies local electric fields, which restricts the industrialization of high voltage direct current (HVDC) gas-insulated transmission lines (GILs). In this paper, the state of art in gas/solid interface charging physics and models, covering areas of charge measurement techniques, charge transport mechanisms, charge related DC surface flashover models, and charge control methods, is reviewed and discussed. Key issues that should be considered in future studies are summarized and proposed. The purpose of this work is to provide a brief update on the most important and latest progress in this research area, and to educate readers as to the current state of the gas-solid interface charging phenomenon, which has seen great progress in the past few years.
\end{abstract}

Keywords: HVDC; GIL; surface flashover; surface charge; charge measurement; material modification

\section{Introduction}

High voltage alternating current (HVAC) gas-insulated transmission lines (GILs) can realize large-capacity power transmission in complex environments, and have been in use since 1960s [1]. However, under high voltage direct current (HVDC), the influence of the surface charge accumulation in spacers must be considered before development of HVDC GIL. At DC voltage, charges transport along electric field lines both in the gas phase and in the spacer bulk, and accumulate on the surface of spacers inside GILs [2]. The local electric field over spacer surface gets more disordered, and is prone to generating a higher local electric field strength as a consequence of the influence of the charge migration $[3,4]$. Under these conditions, a surface flashover is more easily triggered $[5,6]$.

In recent years, the urgent need for HVDC GIL, driven by offshore projects, requires more urgent breakthroughs in this field, and the problem of charge accumulation has become tremendously pronounced [7-9]. As a result, an increasing number of researchers over the past few years have focused on this area, and have made significant efforts to tackle difficult problems that are still a specific challenge to us $[10,11]$. The rapid progress of related research can be reflected both in a surging amount of research, and in special topical issues of the past 5 years [12-16].

Despite the extensive studies and output during the past few years, charge behaviors such as charge generation, transport, and relaxation in dielectrics should be studied, as these fields of research have still not been fully understood [17]. Regarding the above-mentioned problems, related studies have been performed, including charge measurement techniques, charge transport mechanisms, charge related DC surface flashover mechanisms, and charge control methods. There have been review papers published on specific branches, including surface charge transport models and charge tailoring techniques [18,19], metal particles [20], as well as surface charge measurement techniques [7], and related studies have been reviewed.

The propose of this work is to provide a brief update the on most important and latest progress in this research area, and to educate readers as to the current state of the gas-solid interface charging 
phenomenon, which has seen great progress in the past few years. We firstly summarize the research progress of the above-mentioned topics. Research difficulties in this field of research are also discussed. Key issues that should be considered in future studies are summarized and proposed. We hope that the content of this paper can act as a reference and can provide an orientation for relevant study into the surface charging behaviors of HVDC spacers.

\section{Surface Charge Measurement}

The Lichtenberg dust figure method can be used to reflect surface charge distribution based on the property that a charged surface can adsorb dust particles with hetero-polarities, as shown in Figure 1a [21]. Based on the principle that dielectrics can be polarized inside electric fields, the electric field density due to charge accumulation on the surface can be depicted by polarized dielectric particles, as shown in Figure 1b. More details regarding polarized surface charge cluster formation and dust pattern phase transition can be found in the literature [22,23]. In recent years, Kelvin probe methods have been more widely used. As an oscillating feedback capacitive probe, the Kelvin probe is a typical representative of an active electrostatic probe, by which the potential can be obtained from the measured point [7]. The distribution of surface charge density can be obtained by a simulation algorithm based on the surface potential measurement result. The comparison of these two methods is shown in Table 1.

However, at present, it is still very difficult to obtain a "net" surface charge distribution unaffected from the bulk polarization using the above-mentioned methods. Additionally, to calculate the charge density by the surface potential distribution from one side potential measurement introduces large errors, since charges on the opposite side of the spacer affect the potential measurement indirectly, which has already been verified in previous studies [24].

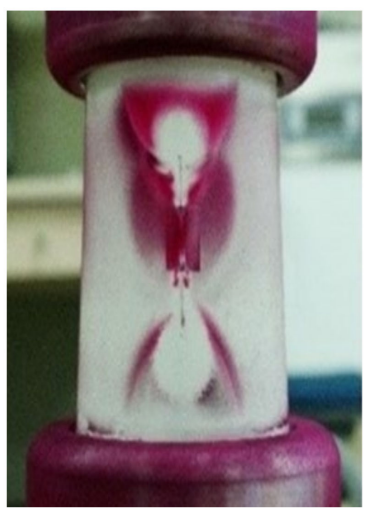

(a)

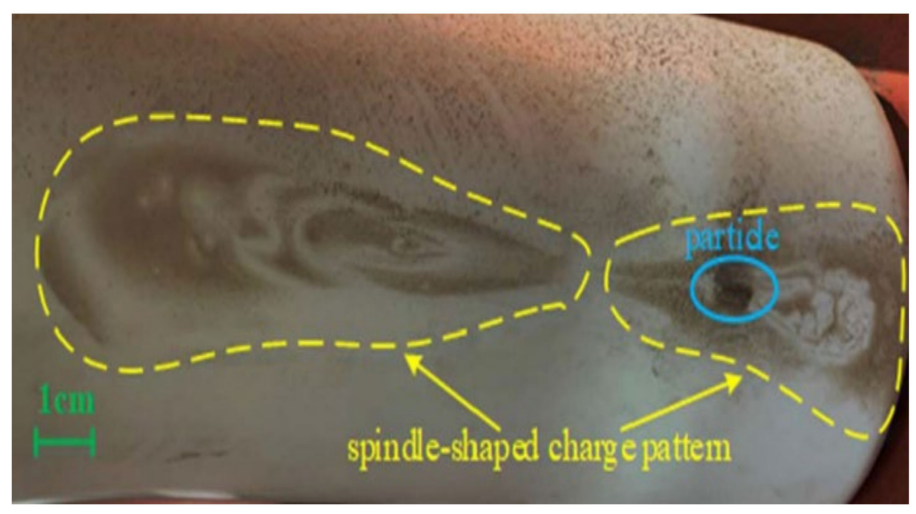

(b)

Figure 1. Measurement results obtained by Lichtenberg dust figure method. (a) Via toner dust [21], and (b) via silicate dust [22].

Table 1. Comparison of the Lichtenberg dust figure method and the Kelvin probe method.

\begin{tabular}{ccc}
\hline Methods & Advantages & Disadvantages \\
\hline & $\begin{array}{c}\text { Measurement result is not restricted by } \\
\text { surface potential value and is not } \\
\text { influenced by charge decay process } \\
\text { during measurement. }\end{array}$ & $\begin{array}{c}\text { Cannot quantitatively characterize } \\
\text { charge density (or electric field } \\
\text { strength); dust adsorbed may have a } \\
\text { certain impact on local electric field. }\end{array}$ \\
\hline Kelvin probe & $\begin{array}{c}\text { Surface potential value can be } \\
\text { quantitatively characterized with a } \\
\text { high sensitivity. }\end{array}$ & $\begin{array}{c}\text { Low spatial resolution and relative low } \\
\text { voltage range; measurement } \\
\text { takes longer. }\end{array}$ \\
\hline
\end{tabular}


Bilateral surface potential measurements of spacers are an option to avoid such influence [24,25]. The influence of probe geometry and errors from spatial resolution should be further calibrated [26]. Additionally, the effect of the internal quick depolarization process on the surface potential measurement is also rarely considered.

\section{Charge Transport and Models}

As early in 1982, Cooke proposed that the discharge in $\mathrm{SF}_{6}$ near the insulator can become a source of hetero-polarity charges [27]. Later, it was discovered that homo-polarity charges injected to the volume might also dominant surface potential polarity [28]. It is generally believed that surface charges can come from the gas phase and bulk of the solid spacer. Various charge accumulation models were proposed based on each individual experimental setup and its results, where the charge sources were believed to be mainly due to uneven material distribution, bulk injection charges, partial discharges (PDs), corona discharges, volume polarization, etc. [29,30].

Pioneering studies by Li proposed a field-dependent theory to explain surface charge patterns and charge origin in spacers [31]. This model confirms that the surface potential measurement result reflects the combined contribution of both the normal component of the bulk leakage current and the gas leakage current that ends in the spacer surface. The charging property of spacers is dominant from the volume below an electric field of $2.5 \mathrm{kV} / \mathrm{mm}$. When the electric field stress is higher than $2.5 \mathrm{kV} / \mathrm{mm}$, the charging property of spacers is dominated by the enhanced gas ionization, due to local sharp protrusions on the grounded conductor surface. The field-dependent model of dominant charge behavior is shown in Figure 2.

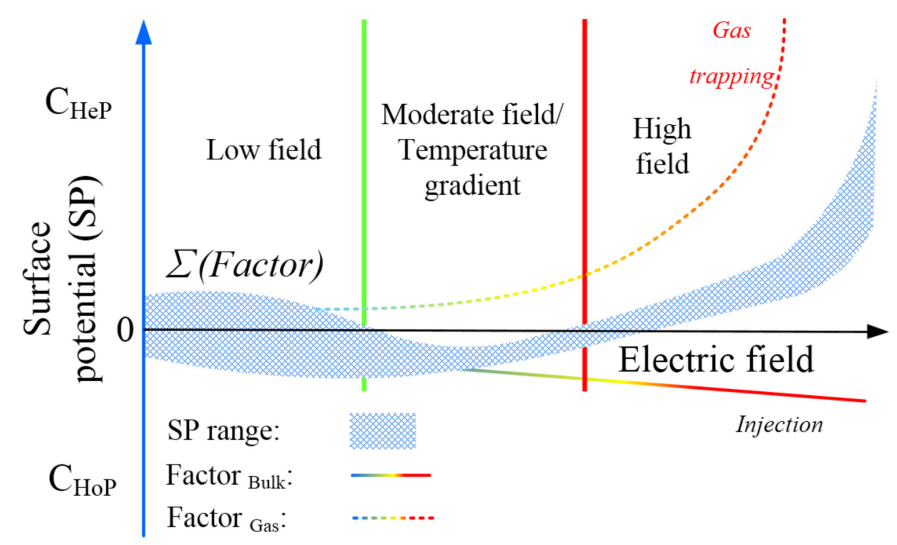

Figure 2. Field-dependent model of dominant charge behavior [31].

This model explains the existing research results and provides a link for the lateral comparison of previous research results from different researchers. However, the following issues still remain unsolved and need further verification:

- The experimental configuration is complicated, as different field strengths appear on various parts of the configuration. It would be better to adopt simpler configurations where the electric field is precisely defined, such as axisymmetric post-type spacers placed between parallel-plate electrodes.

- Due to the lack of calibration of local roughness, the effects of relative humidity and temperature gradient, the division in low-mid-high fields cannot be characterized quantitatively.

- The dimensions of this model need to be further filled and expanded, under the premise of considering the first two suggestions.

These unsolved issues are also key problems limiting the completion of gas/solid interface charging models, and should be further studied. 


\section{Charge Triggered DC Surface Flashover}

Surface flashover is a gas breakdown phenomenon along a dielectric surface. At DC voltage, it can be triggered by different factors that affect surface electric field distribution. Surface charge accumulated at DC voltage causes local electric field distortion, which may induce the flashover along the surface. In 1994, it was reported that the low energy flashover on the spacer surface is likely to be related to surface charge accumulation [32]. The triggering of the flashover is not directly related to the number of surface charges, since it was found that a small amount of charge can also cause a high local electric field [33]. The presence of hetero-polarity charges is more likely to induce a surface flashover [34]. Recent studies have shown that the homo-polarity charges injected into the volume can result in a potential enhancement near the high voltage electrode, which is equivalent to the extension of the high voltage electrode to the direct of the ground electrode. Thereby, an "analogous ineffective region" is expanded, which reduces the flashover inception voltage [35]. This model explains the unpredictable flashover of the insulator with DC application. However, the model is obtained using sheet insulation structures, where the electric field distribution is very different to that of the spacers in GIL. Meanwhile, the charge is likely to accumulate at different insulation interfaces, which may have an influence on the definition of "analogous ineffective region" expansion.

Recent research showed that the unpredictable insulation surface flashover can be triggered by surface charge clusters under DC electric field [23]. The charge cluster is randomly formed when ions originating from local micro-protrusions accumulate on the insulation surface, the edge of which produces a strong electrical field to induce local streamers. These local streamers provide an inducing factor unpredictably triggering surface flashover [23].

In addition to the above, models to explain the unpredictable DC surface flashover of spacers triggered by charge accumulation inside $\mathrm{SF}_{6}$ are still barely studied. It has been verified that both surfaces can be charged with charges of different polarities when DC was applied. Do these charges with different polarities affect the probability of flashover on both sides? What is the process and the mechanism of charge-induced unpredictable flashover? What is the inherent relationship between local charge accumulation (charge properties) and initial electron collapse? The invisibility of surface charge transport at various electric fields, as well as the instantaneous property of surface flashover, both introduce great difficulties into uncovering the mechanism of local charge induced surface flashover. Innovative research ideas or test methods are needed to verify the above issues.

\section{Charge Tailoring Methods}

In order to suppress the surface charge accumulation, material modification methods are useful tools, and have become a hot research field in recent years. The favored surface charge suppression methods should be based on the premise of not reducing other electrical and mechanical properties. The mainstream of the charge regulation techniques is classified based on the following four aspects: (1) suppressing charge injection at the electrode-solid interface, (2) increasing the dissipation of trapped charges, (3) suppressing local electric field distortion, and (4) other methods. Selected representative studies of different modification techniques and their characteristics are shown in Table 2.

As shown in Table 2, the existing research results showed favorable results regarding surface charge suppression from different aspects. $\mathrm{SiO}_{2}$ and $\mathrm{Cr}_{2} \mathrm{O}_{3}$ coatings can suppress surface charge accumulation by introducing deep traps that limit the conducting current from the volume of the spacer [36,37]. By means of fluorination, plasma treatment, and surface roughness treatment, shallow traps can be introduced, which is beneficial to surface charge decay [38-40]. Nonlinear material doping can also be used as a way to modify local electric field and increase the stability of the system [41], while the charge adaptively controls methods to take advantage of surface charges themselves, to limit the charge density in the charge control region adaptively [42,43]. 
Table 2. Representative works of different modification methods and their characteristics.

\begin{tabular}{|c|c|c|}
\hline Categories & Methods & Characteristics \\
\hline \multirow{2}{*}{$\begin{array}{l}\text { Suppressing } \\
\text { charge trapping }\end{array}$} & $\mathrm{SiO}_{2}$ doping [36] & $\begin{array}{l}\text { Restraining volume leakage current by decreasing } \\
\text { bulk conductivity. }\end{array}$ \\
\hline & $\mathrm{Cr}_{2} \mathrm{O}_{3}$ coatings [37] & $\begin{array}{l}\text { Restraining volume injection by introducing deep traps } \\
\text { between electrode and dielectrics. }\end{array}$ \\
\hline \multirow{3}{*}{$\begin{array}{l}\text { Increasing } \\
\text { charge }\end{array}$} & Fluorination [38] & $\begin{array}{l}\text { Controlling surface conductivity by means of } \\
\text { modulating fluorination temperature and time duration. }\end{array}$ \\
\hline & Plasma [39] & $\begin{array}{l}\text { Increasing surface conductivity by means of changing } \\
\text { the surface nanostructure and decreasing the depth of } \\
\text { energy levels. }\end{array}$ \\
\hline & $\begin{array}{l}\text { Surface roughness } \\
\text { treatment [40] }\end{array}$ & $\begin{array}{l}\text { A rougher surface increases surface conductivity and } \\
\text { introduces deep traps, which results in a declination of } \\
\text { surface charges. }\end{array}$ \\
\hline $\begin{array}{l}\text { Optimizing } \\
\text { local electric } \\
\quad \text { field }\end{array}$ & $\begin{array}{l}\text { Nonlinear conductive } \\
\text { coating [ } 41]\end{array}$ & $\begin{array}{c}\text { Uniforming the electric field distribution and } \\
\text { accelerating transient process thanks to the nonlinear } \\
\text { property of the coating. }\end{array}$ \\
\hline Other & $\begin{array}{l}\text { Charge adaptively } \\
\text { control spacer } \\
\text { (CACS) }[42,43]\end{array}$ & $\begin{array}{c}\text { Controlling charging position using a bowl shape } \\
\text { structure and decreasing charge amount thanks to the } \\
\text { nonlinear property of the charge adaptively } \\
\text { controlling region. }\end{array}$ \\
\hline
\end{tabular}

All the above-mentioned methods can be effective in surface charge suppression. However, it should be considered that whether or not it is still a problem that the current research results using small-sized samples can be smoothly transplanted to large-sized spacers. In addition, many studies have measured the charge accumulation and flashover voltages in air, which often run counter to the ultimate goal of the study, i.e., to restrain surface charge accumulation of spacers inside $\mathrm{SF}_{6}$ with higher gas pressures. The electric field under $\mathrm{SF}_{6}$ or the alternative insulating gas mixtures is completely different compared with that in air, and the charge behavior and flashover induction mechanism under different electric fields are also different. This problem is more pronounced when nonlinear materials are applied, since the flashover voltage in air is much lower than the flashover voltage in $\mathrm{SF}_{6}$, the properties of nonlinear materials in low electric field will be different from those in $\mathrm{SF}_{6}$. In addition, although some surface treatment methods, such as coating, are simple to obtain, and can be slightly adjusted on the basis of the existing AC insulator, the aging mechanism of this coating or surface structures and the operational reliability under temperature cycling still need to be further verified. From this point of view, it is often more reliable to use a one-time curing process to prepare new types of spacers.

\section{Problems and Outlooks}

As mentioned above, there is still plenty of work to be done to tackle the problems and push the research frontiers in this area further forward. Based on these problems, here are some outlooks, as follows:

- The physical process for the formation of dust figure still needs to be studied. Currently, it is still difficult to clarify the relation between the self-assembled dust patterns and surface potential/charge/electric field distribution. More basic research needs to be performed. Meanwhile, the study of online surface charge measurement techniques is more favored by engineers and researchers, which are still under research.

- Since the local roughness of conductors directly influence the surface charge origins, while the relative humidity can significantly increase the ionization process, the synergy effect of the relation 
between relative humidity and surface roughness of conductors should be further studied as the basis of the design of DC GIL.

- Some flashover models at DC voltage have been put forward; however, still there is no direct evidence on how charge transports before triggering surface flashover. Meanwhile, there is still a lack of research into the charge transport property in novel insulating gases.

- Most of the surface charge decay solution can decay charges. However, the anti-aging property of these methods should be evaluated. Additionally, trying the techniques using large sized spacers in $\mathrm{SF}_{6}$ other than insulation films in air is suggested.

\section{Conclusions}

This paper reviews and discusses the achievements regarding different research topics in surface charging phenomena of HVDC spacers. Key issues that should be considered in future studies are summarized and listed. The purpose of this work is to provide a brief update on the most important and latest progress in this research area, and to educate readers as to the current state of the gas-solid interface charging phenomenon, which has seen great progress in the past few years.

Author Contributions: Validation by J.C. and S.A. (Serge Agnel); formal analysis and investigation by S.A. (Serge Agnel) and J.C.; resources and data curation by S.A. (Shakeel Akram); writing-original draft preparation, S.A. (Shakeel Akram); writing-review and editing by S.A. (Shakeel Akram). All authors have read and agreed to the published version of the manuscript.

Funding: This research received no external funding.

Conflicts of Interest: The authors declare no conflict of interest that they have no known competing financial interests or personal relationships that could have appeared to influence the work reported in this paper.

\section{References}

1. Hermann, K. Gas-Insulated Transmission Lines (GIL); John Wiley \& Sons, Ltd.: Hoboken, NJ, USA; IEEE Press: Piscataway, NJ, USA, 2012.

2. Li, C.; Hu, J.; Lin, C.; Zhang, B.; Zhang, G.; He, J. Surface charge migration and DC surface flashover of surface-modified epoxy-based insulators. J. Phys. D Appl. Phys. 2017, 50, 065301. [CrossRef]

3. Du, B.; Liang, H.; Li, J.; Zhang, C. Temperature dependent surface potential decay and flashover characteristics of epoxy/SiC composites. IEEE Trans. Dielectr. Electr. Insul. 2018, 25, 631-638. [CrossRef]

4. Xue, J.-Y.; Chen, J.-H.; Dong, J.-H.; Wang, H.; Li, W.-D.; Deng, J.-B.; Zhang, G.-J. The regulation mechanism of $\mathrm{SiC} /$ epoxy coatings on surface charge behavior and flashover performance of epoxy/alumina spacers. J. Phys. D Appl. Phys. 2019, 52, 405502. [CrossRef]

5. Qi, B.; Gao, C.; Li, C.; Xiong, J. The influence of surface charge accumulation on flashover voltage of GIS/GIL basin insulator under various voltage stresses. Int. J. Electr. Power Energy Syst. 2019, 105, 514-520. [CrossRef]

6. Zhang, Z.; Wang, Z.; Teyssedre, G.; Shahsavarian, T.; Baferani, M.A.; Chen, G.; Lin, C.; Zhang, B.; Riechert, U.; Lei, Z.; et al. Gas-solid interface charge tailoring techniques: What we grasped and where to go. Nanotechnology 2020. [CrossRef]

7. Zhang, L.; Lin, C.; Li, C.; Suraci, S.V.; Chen, G.; Riechert, U.; Shahsavarian, T.; Hikita, M.; Tu, Y.; Zhang, Z.; et al. Gas-solid interface charge characterisation techniques for HVDC GIS/GIL insulators. High Volt. 2020, 5, 95-109. [CrossRef]

8. Ghaffarinejad, A.; Hasani, J.Y. Modeling of triboelectric charge accumulation dynamics at the metal-insulator interface for variable capacitive structures: Application to triboelectric Nano generators. Appl. Phys. A 2019, 125, 259. [CrossRef]

9. Khatua, S.; Preetha, P. Effect of Surface Charge Accumulation on Electric Field Computation in $\mathrm{CO}_{2}$ filled GIS. In Proceedings of the 2019 IEEE Region 10 Symposium (TENSYMP), Kolkata, India, 7-9 June 2019; pp. 282-286.

10. Li, C.; He, J.; Hu, J. Surface morphology and electrical characteristics of direct fluorinated epoxy-resin/alumina composite. IEEE Trans. Dielectr. Electr. Insul. 2016, 23, 3071-3077. [CrossRef]

11. Fujinami, H.; Takuma, T.; Yashima, M.; Kawamoto, T. Mechanism and effect of DC charge accumulation on $\mathrm{SF}_{6}$ gas insulated spacers. IEEE Trans. Power Deliv. 1989, 4, 1765-1772. [CrossRef] 
12. Fabiani, D.; Li, C.; Zhang, G.; Mazzanti, G.; Teyssedre, G.; He, J. Interface charging phenomena for dielectric materials. High Volt. 2020, 5, 93-94.

13. Li, C.; Cao, Y.; Li, Q.; Riechert, U.; Fabiani, D. Gas-solid interface charging physics. Nanotechnology. 2020. Available online: https://iopscience.iop.org/journal/0957-4484/page/Focus-on-Gas-Solid-Interface-ChargingPhysics (accessed on 3 December 2020).

14. Li, C.; He, J. Advanced dielectrics for gas-insulated transmission lines. IEEE Trans. Dielectr. Electr. Insul. 2018, 25, 1151. [CrossRef]

15. Tu, Y.; Chen, G.; Li, C.; Wang, C.; Ma, G.; Zhou, H.; Ai, X.; Cheng, Y. $\pm 100-k V$ HVDC SF 6/N 2 Gas-insulated transmission line. IEEE Trans. Power Deliv. 2019, 35, 735-744. [CrossRef]

16. Li, C.; Lin, C.; Zhang, B.; Li, Q.; Liu, W.; Hu, J.; He, J. Understanding surface charge accumulation and surface flashover on spacers in compressed gas insulation. IEEE Trans. Dielectr. Electr. Insul. 2018, 25, 1152-1166. [CrossRef]

17. Xue, J.-Y.; Chen, J.-H.; Dong, J.-H.; Deng, J.-B.; Zhang, G. Enhancing flashover performance of alumina/epoxy spacers by adaptive surface charge regulation using graded conductivity coating. Nanotechnology 2020, 31, 364002. [CrossRef]

18. Li, C.; Hu, J.; Lin, C.; Zhang, B.; Zhang, G.; He, J. Fluorine gas treatment improves surface degradation inhibiting property of alumina-filled epoxy composite. AIP Adv. 2016, 6, 025017. [CrossRef]

19. Li, C.; Xu, Y.; Lin, C.; Chen, G.; Tu, Y.; Zhou, Y.; Lei, Z.; Han, T.; Suraci, S.V.; Wang, J.; et al. Surface charging phenomena on HVDC spacers for compressed SF 6 insulation and charge tailoring strategies. CSEE J. Power Energy Syst. 2019, 6, 83-99.

20. Wang, J.; Hu, Q.; Chang, Y.; Wang, J.; Liang, R.; Tu, Y.; Li, C.; Li, Q. Research progress on metal particle contamination in GIS/GIL. CSEE J. Power Energy Syst. 2019. [CrossRef]

21. Xu, Y.; Liu, W.; Gao, W. Research on the influence factor of the dust figure used for the measurement of the surface charge and electric field distribution of GIS insulator under AC voltage. Insul. Surge Arresters 2020, 3, 205-212. (In Chinese)

22. Xing, L.; Weidong, L.; Yuan, X.; Weijiang, C.; Jiangang, B.; Li, X.; Liu, W.; Xu, Y.; Chen, W. Surface charge accumulation and pre-flashover characteristics induced by metal particles on the insulator surfaces of $1100 \mathrm{kV}$ GILs under AC voltage. High Volt. 2020, 5, 134-142. [CrossRef]

23. Li, C.; Zhu, Y.; Hu, J.; Li, P.D.Q.; Zhang, P.B.; He, P.D.J. Charge cluster triggers unpredictable insulation surface flashover in pressurized $\mathrm{SF}_{6}$. J. Phys. D Appl. Phys. 2020, 54, 015308. [CrossRef]

24. Lin, C.J.; Li, C.Y.; He, J.L.; Hu, J.; Zhang, B. Surface charge inversion algorithm based on bilateral surface potential measurements of cone-type spacer. IEEE Trans. Dielectr. Electr. Insul. 2017, 24, 1905-1912. [CrossRef]

25. Kumada, A.; Okabe, S. Measurement of surface charge on opposite sides of a planar insulator using an electrostatic probe. IEEE Trans. Dielectr. Electr. Insul. 2004, 11, 919-928. [CrossRef]

26. Kumada, A.; Okabe, S.; Hidaka, K. Influences of probe geometry and experimental errors on spatial resolution of surface charge measurement with electrostatic probe. IEEE Trans. Dielectr. Electr. Insul. 2005, 12, 1172-1181. [CrossRef]

27. Cooke, C.M. Charging of insulator surfaces by ionization and transport in gases. IEEE Trans. Dielectr. Electr. Insul. 1982, 2, 172-178. [CrossRef]

28. Ma, G.-M.; Zhou, H.-Y.; Liu, S.-P.; Wang, Y.; Zhao, S.-J.; Lu, S.-J.; Li, C.-R.; Tu, Y.-P. Measurement and simulation of charge accumulation on a disc spacer with electro-thermal stress in $\mathrm{SF}_{6}$ gas. IEEE Trans. Dielectr. Electr. Insul. 2018, 25, 1221-1229.

29. Kindersberger, J.; Lederle, C. Surface charge decay on spacers in air and sulfurhexafluorid-Part II: Measurement. IEEE Trans. Dielectr. Electr. Insul. 2008, 15, 949-957. [CrossRef]

30. Tschentscher, M.; Franck, C.M. Conduction processes in gas-insulated HVDC equipment: From saturated ion currents to micro-discharges. IEEE Trans. Dielectr. Electr. Insul. 2018, 25, 1167-1176. [CrossRef]

31. Li, C.Y.; Lin, C.J.; Chen, G.; Tu, Y.P.; Zhou, Y.; Li, Q.; Zhang, B.; He, J.L. Field-dependent charging phenomenon of HVDC spacers based on dominant charge behaviors. Appl. Phys. Lett. 2019, 114, 202904. [CrossRef]

32. Wang, C. Physical model for surface charge supported flashover. In Gaseous Dielectrics VII; Springer: Boston, MA, USA, 1994; pp. 519-525. 
33. Winter, A.; Kindersberger, J. Surface charge accumulation on insulating plates in $\mathrm{SF}_{6}$ and the effect on $\mathrm{DC}$ and AC breakdown voltage of electrode arrangements. In Proceedings of the Annual Report Conference on Electrical Insulation and Dielectric Phenomena, Cancun, Mexico, 20-24 October 2002; pp. 757-761.

34. Kumara, S.; Alam, S.; Hoque, I.R.; Serdyuk, Y.V.; Gubanski, S.M. DC flashover characteristics of a polymeric insulator in presence of surface charges. IEEE Trans. Dielectr. Electr. Insul. 2012, 19, 1084-1090. [CrossRef]

35. Li, C.Y.; Hu, J.C.; Lin, J.; He, J.L. The neglected culprit of DC surface flashover-electron migration under temperature gradients. Sci. Rep. 2017, 7, 1-11. [CrossRef]

36. Chu, P.; Zhang, H.; Zhao, J.; Gao, F.; Guo, Y.; Dang, B.; Zhang, Z. On the volume resistivity of silica nanoparticle filled epoxy with different surface modifications. Compos. Part A Appl. Sci. Manuf. 2017, 99, 139-148. [CrossRef]

37. Li, C.Y.; Hu, J.; Lin, C.J.; He, J. The control mechanism of surface traps on surface charge behavior in alumina-filled epoxy composites. J. Phys. D Appl. Phys. 2016, 49, 445304. [CrossRef]

38. Akram, S.; Wu, G.N.; Gao, G.Q.; Liu, Y. Effect of surface discharge on nano filled polyimide film under square voltage. IEEE Electr. Insul. Conf. (EIC) 2015, 226-229. [CrossRef]

39. Akram, S.; Yang, Y.; Zhong, X.; Bhutta, S.; Wu, G.; Castellon, J.; Zhou, K. Influence of nano layer structure of polyimide film on space charge behavior and trap levels. IEEE Trans. Dielectr. Electr. Insul. 2018, 25, 1461-1469. [CrossRef]

40. Akram, S.; Castellon, J.; Meng, P.F.; Castellon, J.; Agnel, S.; Wang, P.; Nazir, M.T.; Chen, Y.D.; Hussain, H. Charge transport and trapping of surface modified stator coil insulation of motors. IEEE Trans. Dielectr. Electr. Insul. 2020, in press.

41. Li, J.; Liang, H.C.; Du, B.X.; Wang, Z.H. Surface functional graded spacer for compact HVDC gaseous insulated system. IEEE Trans. Dielectr. Electr. Insul. 2019, 26, 664-667. [CrossRef]

42. Li, C.Y.; Lin, C.J.; Hu, J.; Liu, W.D.; Li, Q.; Zhang, B.; He, S.; Yang, Y.; Liu, F.; He, J.L. Novel HVDC spacers by adaptively controlling surface charges-Part I: Charge transport and control strategy. IEEE Trans. Dielectr. Electr. Insul. 2018, 25, 1238-1247.

43. Li, C.Y.; Lin, C.J.; Yang, Y.; Zhang, B.; Liu, W.D.; Li, Q.; Hu, J.; He, S.; Liu, X.L.; He, J.L. Novel HVDC spacers by adaptively controlling surface charges-Part II: Experiment. IEEE Trans. Dielectr. Electr. Insul. 2018, $25,1248-1258$.

Publisher's Note: MDPI stays neutral with regard to jurisdictional claims in published maps and institutional affiliations.

(C) 2020 by the authors. Licensee MDPI, Basel, Switzerland. This article is an open access article distributed under the terms and conditions of the Creative Commons Attribution (CC BY) license (http://creativecommons.org/licenses/by/4.0/). 